\title{
A General Synthesis Strategy for Hierarchical Porous Metal Oxide Hollow Spheres
}

\author{
Huadong Fu, ${ }^{1}$ Feng Ren, ${ }^{2}$ Weiming Su, ${ }^{2}$ Jinlin Yang, ${ }^{2}$ and Ruiping Liu ${ }^{2}$ \\ ${ }^{1}$ Institute for Advanced Materials and Technology, University of Science and Technology Beijing, Beijing 100083, China \\ ${ }^{2}$ Department of Materials Science and Engineering, China University of Mining \& Technology, Beijing 100083, China \\ Correspondence should be addressed to Ruiping Liu; 201402@cumtb.edu.cn
}

Received 28 July 2015; Accepted 6 September 2015

Academic Editor: Ruomeng Yu

Copyright (c) 2015 Huadong Fu et al. This is an open access article distributed under the Creative Commons Attribution License, which permits unrestricted use, distribution, and reproduction in any medium, provided the original work is properly cited.

\begin{abstract}
The hierarchical porous $\mathrm{TiO}_{2}$ hollow spheres were successfully prepared by using the hydrothermally synthesized colloidal carbon spheres as templates and tetrabutyl titanate as inorganic precursors. The diameter and wall thickness of hollow $\mathrm{TiO}_{2}$ spheres were determined by the hard templates and concentration of tetrabutyl titanate. The particle size, dispersity, homogeneity, and surface state of the carbon spheres can be easily controlled by adjusting the hydrothermal conditions and adding certain amount of the surfactants. The prepared hollow spheres possessed the perfect spherical shape, monodispersity, and hierarchically pore structures, and the further experiment verified that the present approach can be used to prepare other metal oxide hollow spheres, which could be used as catalysis, fuel cells, lithium-air battery, gas sensor, and so on.
\end{abstract}

\section{Introduction}

Compared to the solid particles, hollow spheres have attracted much attention in recent years due to its outstanding properties, such as the controlled pore structure, low density, high specific surface area, high pore volume, and superior thermal and mechanical stability, in which widespread potential applications in catalysts, gas sensors, coatings, energy storage, conversion, and so forth can be found [1-4]. For example, the $\mathrm{Co}_{3} \mathrm{O}_{4}$ spheres with hollow structure could be used as an excellent catalyst for many key applications [5-9]; due to their large specific surface area and hierarchical pore structures, $\mathrm{TiO}_{2}$ hollow spheres exhibit excellent photocatalytic performance [10-14], while $\mathrm{SnO}_{2}$ hollow spheres could be used as an anode material for lithium ion batteries with high efficiency [15-18].

Recently, the design strategies and preparation methods of the hollow nano- or microspheres have been reported by many researchers, and the templates assisted synthesized method was commonly used as an effective approach to prepare hierarchical hollow spheres. The hard templates such as polymethyl methacrylate microspheres, polymer latex particles, polystyrene microspheres, and silica spheres and soft templates such as emulsion droplets, twelve sodium dodecyl sulfate (SDS), micelles, and gas bubbles were usually used [19-22]. The synthesis and pore structure regulation of hollow spheres with size and shape controlled morphologies may obtain other excellent performances and broaden its applications. Among the above templates, the monodispersed carbonaceous microspheres synthesized by hydrothermally treating of aqueous solutions of glucose and sugar were thought to be an ideal hard template for preparation of the hollow spheres [23]. Due to the existence of the functional groups which were located at the surface of the colloidal carbon spheres, the templates were suited for the absorption of cationic metal ions and precipitation of metal precursors. Therefore, in the present work, we aimed to report a general synthesis approach applicable to prepare metal oxide hollow spheres with tunable structure by using the hydrothermally synthesized colloidal carbon spheres as the hard templates.

\section{Experimental Procedure}

2.1. Synthesis of Carbon Spheres. The colloidal carbon spheres used in the present study were prepared by hydrothermally treating of aqueous solutions of glucose. Typically, 9 grams of 


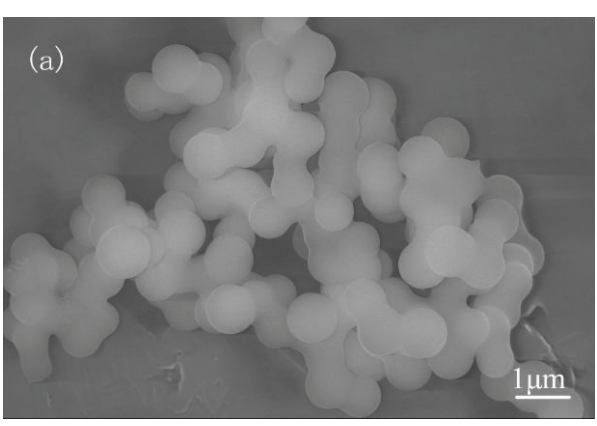

(a)

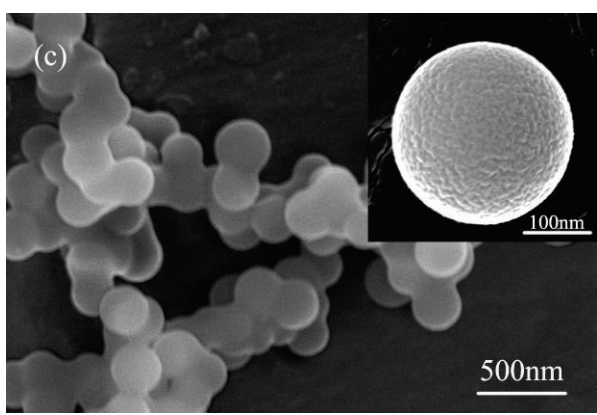

(c)

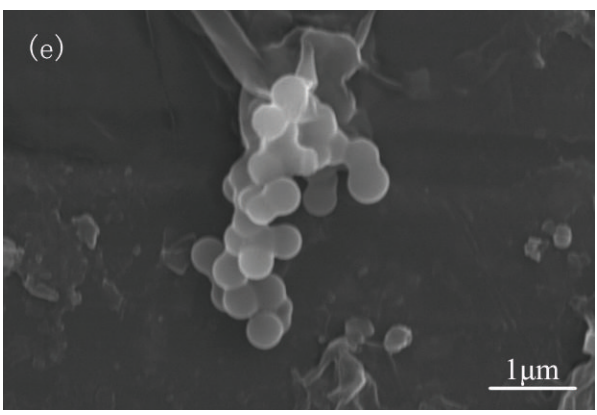

(e)

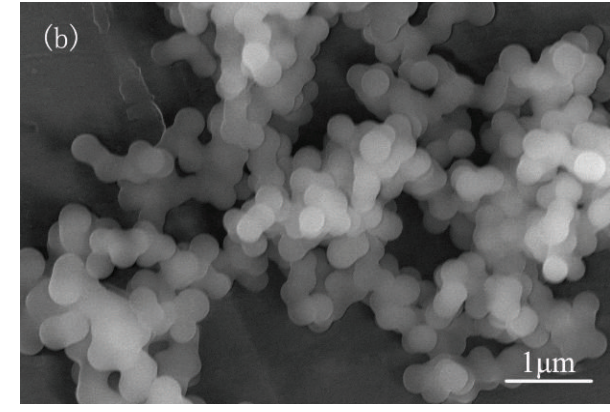

(b)

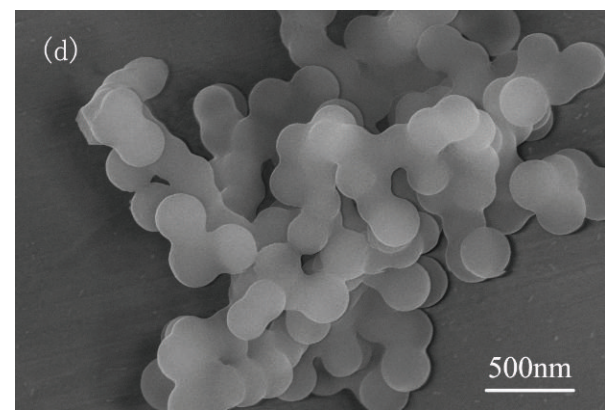

(d)

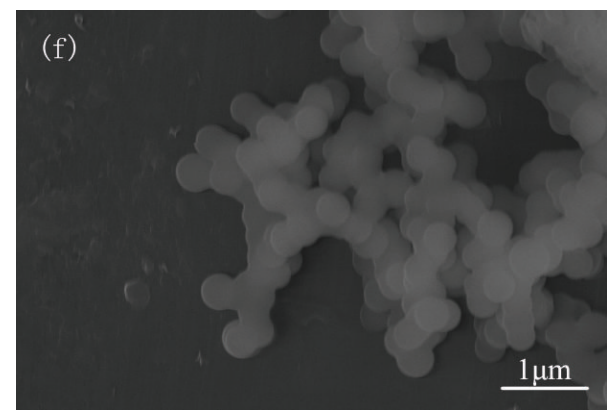

(f)

FIGURE 1: SEM photographs of carbon spheres prepared by different concentration of glucose, hydrothermal temperature, and time. (a) $0.5 \mathrm{~mol} / \mathrm{L}, 220^{\circ} \mathrm{C}, 12 \mathrm{~h}$; (b) $0.5 \mathrm{~mol} / \mathrm{L}, 200^{\circ} \mathrm{C}, 12 \mathrm{~h}$; (c) $0.5 \mathrm{~mol} / \mathrm{L}, 180^{\circ} \mathrm{C}, 12 \mathrm{~h}$; (d) $0.5 \mathrm{~mol} / \mathrm{L}, 220^{\circ} \mathrm{C}, 10 \mathrm{~h}$; (e) $0.5 \mathrm{~mol} / \mathrm{L}, 220^{\circ} \mathrm{C}, 8 \mathrm{~h}$; (f) $0.75 \mathrm{~mol} / \mathrm{L}$, $220^{\circ} \mathrm{C}, 12 \mathrm{~h}$.

glucose (Beijing Chemical Reagent Factory, analytical purity) was dissolved in $90 \mathrm{~mL}$ deionized (DI) water to form a clear solution, which was then transferred to a $100 \mathrm{~mL}$ Teflonsealed autoclave and maintained at certain temperature and time. The resultant black products were separated and purified by centrifugation and washed repeatedly in DI water and ethanol for three times, respectively, and finally dried in a vacuum oven at $80^{\circ} \mathrm{C}$ for $6 \mathrm{~h}$. In order to regulate the dispersity and particle size of the as-obtained carbon spheres, the different hydrothermal treatment parameters and different kinds and amounts of the surfactants were used in the preparation of the carbon spheres.

2.2. Preparation of Metal Oxide Hollow Spheres. Take $\mathrm{TiO}_{2}$ as an example, the details of a typical experiment for the synthesis of $\mathrm{TiO}_{2}$ hollow spheres are described as follows. Firstly, $5 \mathrm{~mL}$ tetrabutyl titanate was dissolved in $50 \mathrm{~mL}$ ethanol to form a clear solution, and then 0.1 grams of the newly synthesized carbon spheres was dispersed in the above suspension with the aid of ultrasonication. After stirred for $2 \mathrm{~h}, 20 \mathrm{~mL}$ of the mixed solutions of ethanol and DI water with the volume ratio of $5: 1$ was added dropwise to the suspension under vigorous stirring. The mixture was aged for $1 \mathrm{~h}$ and then subjected to centrifugation and washing to remove impurities and dried in a vacuum oven at $60^{\circ} \mathrm{C}$ for $5 \mathrm{~h}$. Finally, the $\mathrm{TiO}_{2}$ hollow spheres were obtained by strengthening the shell structure and removing the carbon spheres of the carbontitania composites calcined in air at $450-850^{\circ} \mathrm{C}$ (heating rate of $2^{\circ} \mathrm{C} / \mathrm{min}$ ) for $4 \mathrm{~h}$.

2.3. Characterization. The calcination procedure was determined by the thermogravimetric (TG) and differential scanning calorimetry (DSC) analysis. Nicolet Magna 750 was used to measure the FTIR spectra of carbon spheres, and the 


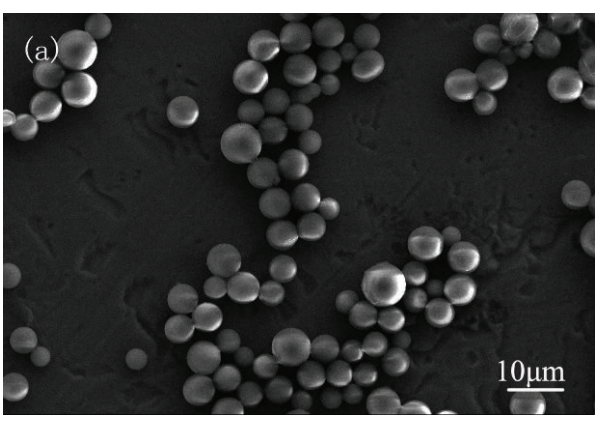

(a)

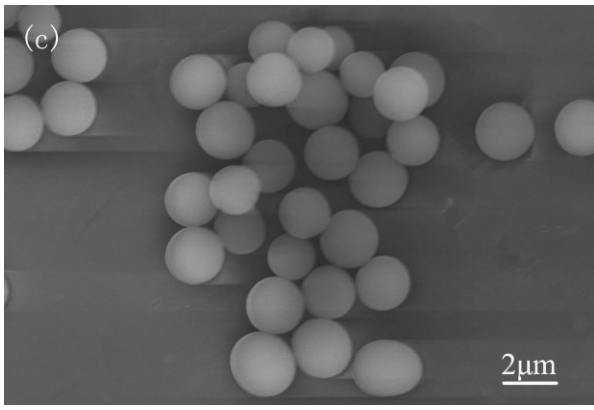

(c)

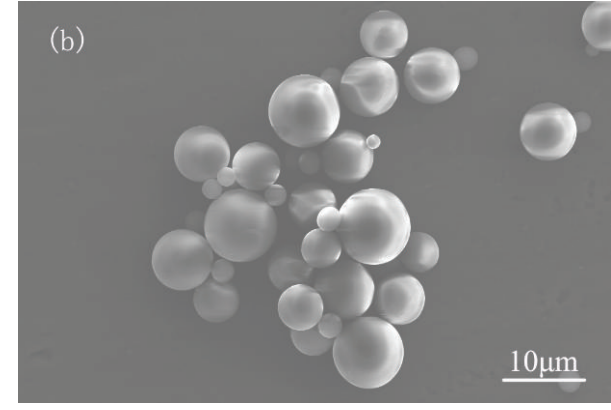

(b)

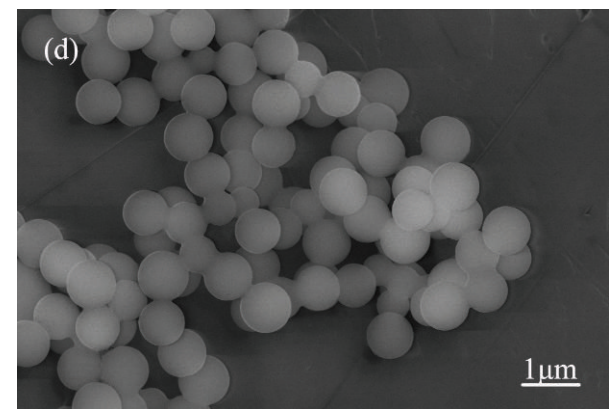

(d)

FiguRE 2: SEM photographs of carbon spheres prepared by adding different kinds and amounts of the surfactants. (a) $0.005 \mathrm{~mol}^{2} \mathrm{~L} \mathrm{NH} \cdot \mathrm{H}_{2} \mathrm{O}$; (b) $0.015 \mathrm{~mol} / \mathrm{L} \mathrm{NH} \cdot \mathrm{H}_{2} \mathrm{O}$; (c) $0.005 \mathrm{~mol} / \mathrm{L} \mathrm{CTAB}$; (d) $0.015 \mathrm{~mol} / \mathrm{L} \mathrm{CTAB}$.

wave number region ranged from 4000 to $500 \mathrm{~cm}^{-1}$ with 64 scans at $8 \mathrm{~cm}^{-1}$ resolution. X-ray diffraction (XRD) with the scanning speed of $4^{\circ} / \mathrm{min}$ from 20 to $80^{\circ}$ was carried out on a Bruker D8-Advance diffractometer using Ni filtered $\mathrm{Cu} \mathrm{K \alpha}$ radiation. The applied current and voltage were $40 \mathrm{~mA}$ and $40 \mathrm{kV}$, respectively. The microstructures of the carbon spheres and hollow $\mathrm{TiO}_{2}$ spheres were observed by scanning electron microscopy (Carl Zeiss Jena scanning microscope, SEM) and transmission electron microscopy (JEOL JEM-2011, TEM). BET-surface area was measured by $\mathrm{N}_{2}$ adsorption at liquid nitrogen temperature using a NOVA4000 automated gas sorption system.

\section{Results and Discussion}

3.1. Synthesis of Carbon Spheres. Figure 1 shows the SEM images of the as-prepared carbon spheres synthesized at different conditions. It can be seen that the dispersity and particle size of the as-synthesized carbon spheres were influenced by hydrothermal time, temperature, and concentration of glucose. With decreasing of the hydrothermal temperature, shortening of the hydrothermal time, and reducing of the concentration of glucose, the particle size of the colloidal carbon spheres decreased, and, meanwhile, the dispersity of the carbon spheres was improved. For example, the particle size of the carbon spheres decreased from $500 \mathrm{~nm}$ to $350 \mathrm{~nm}$ when the hydrothermal temperature decreased from $220^{\circ} \mathrm{C}$ to $180^{\circ} \mathrm{C}$ (Table 1). On the other hand, with increasing of the hydrothermal temperature and hydrothermal time, the particle size of carbon spheres tended to be monodispersed. It also can be found that the as-synthesized carbon spheres exhibit rough and porous surface, which will impart the carbon spheres with low density and large specific surface area.

The hydrothermal synthesis of carbon spheres can also be divided into two stages, including nucleation and growth. The increases of temperature in the early stage of synthesis process led to dehydration and condensation of the glucose molecules, and the polysaccharide molecular was formed. With extending the hydrothermal time, the polysaccharide was further polymerized to form a polymer chain, and the carbon spheres nuclei were formed by the cross linking of polymer chain. Then polymer polymerization occurred in the surface of nuclei, namely, the growth of the carbon spheres, and after further dehydration and carbonization the carbon spheres with certain size were obtained.

In order to further regulate the dispersity and particle size of the carbon spheres, the hydrothermal temperature and time were fixed to $200^{\circ} \mathrm{C}$ and $10 \mathrm{~h}$, respectively, and the different kinds and amounts of the surfactant were added in the solution. The typical SEM images are shown in Figure 2. It can be seen clearly that the morphologies and particle size of carbon spheres can be changed obviously when the surfactants were added, and the dispersity of the carbon spheres was improved, accompanied by decreasing the homogeneity of the carbon spheres. With increasing of the ammonia concentration from $0.005 \mathrm{~mol} / \mathrm{L}$ to $0.015 \mathrm{~mol} / \mathrm{L}$, the particle size of the carbon spheres increased from $2-4 \mu \mathrm{m}$ to $6-9 \mu \mathrm{m}$. The 
TABLE 1: The diameter of the as-synthesized carbon spheres.

\begin{tabular}{|c|c|c|c|c|}
\hline $\begin{array}{l}\text { Concentration of } \\
\text { the glucose }(\mathrm{mol} / \mathrm{L})\end{array}$ & $\begin{array}{c}\text { Hydrothermal } \\
\text { temperature }\left({ }^{\circ} \mathrm{C}\right)\end{array}$ & $\begin{array}{l}\text { Hydrothermal } \\
\text { time (h) }\end{array}$ & Additives & $\begin{array}{l}\text { Diameter of the } \\
\text { carbon spheres }\end{array}$ \\
\hline 0.5 & 220 & 12 & - & $500 \mathrm{~nm}$ \\
\hline 0.5 & 200 & 12 & - & $400 \mathrm{~nm}$ \\
\hline 0.5 & 180 & 12 & - & $350 \mathrm{~nm}$ \\
\hline 0.5 & 220 & 10 & - & $450 \mathrm{~nm}$ \\
\hline 0.5 & 220 & 8 & - & $430 \mathrm{~nm}$ \\
\hline 0.75 & 180 & 12 & - & $450 \mathrm{~nm}$ \\
\hline 0.75 & 220 & 12 & - & $520 \mathrm{~nm}$ \\
\hline $1 \mathrm{~m}$ & 220 & 12 & - & $600 \mathrm{~nm}$ \\
\hline 0.5 & 200 & 10 & Ammonia $0.005 \mathrm{~mol} / \mathrm{L}$ & $2-4 \mu \mathrm{m}$ \\
\hline 0.5 & 200 & 10 & Ammonia $0.015 \mathrm{~mol} / \mathrm{L}$ & $6-9 \mu \mathrm{m}$ \\
\hline 0.5 & 200 & 10 & CTAB $0.005 \mathrm{~mol} / \mathrm{L}$ & $1-2 \mu \mathrm{m}$ \\
\hline 0.5 & 200 & 10 & CTAB $0.015 \mathrm{~mol} / \mathrm{L}$ & $700 \mathrm{~nm}$ \\
\hline
\end{tabular}

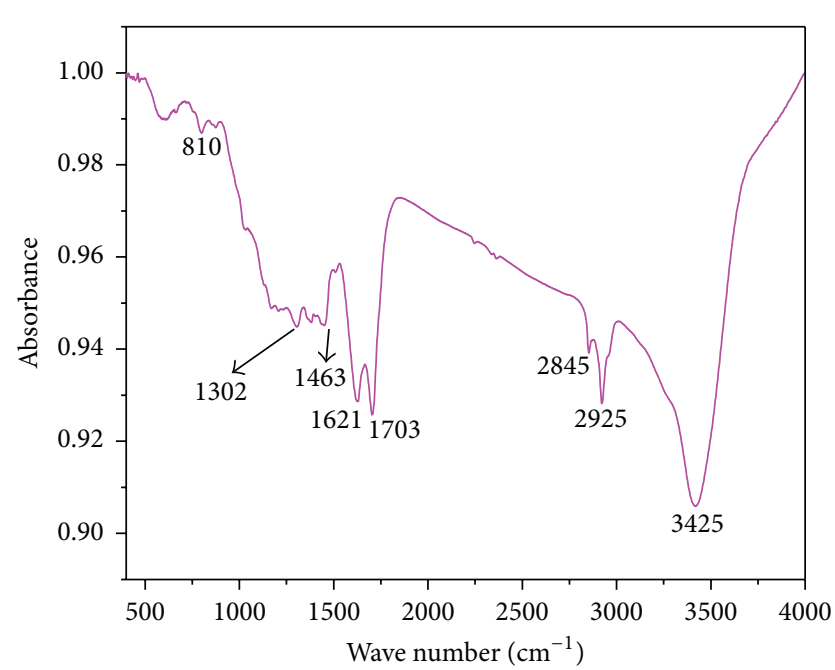

(a)

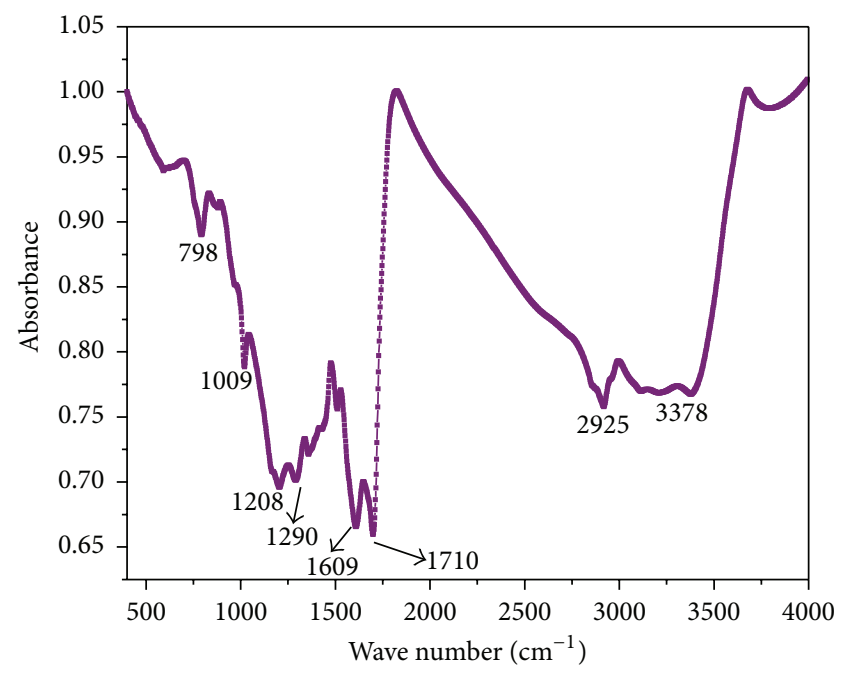

(b)

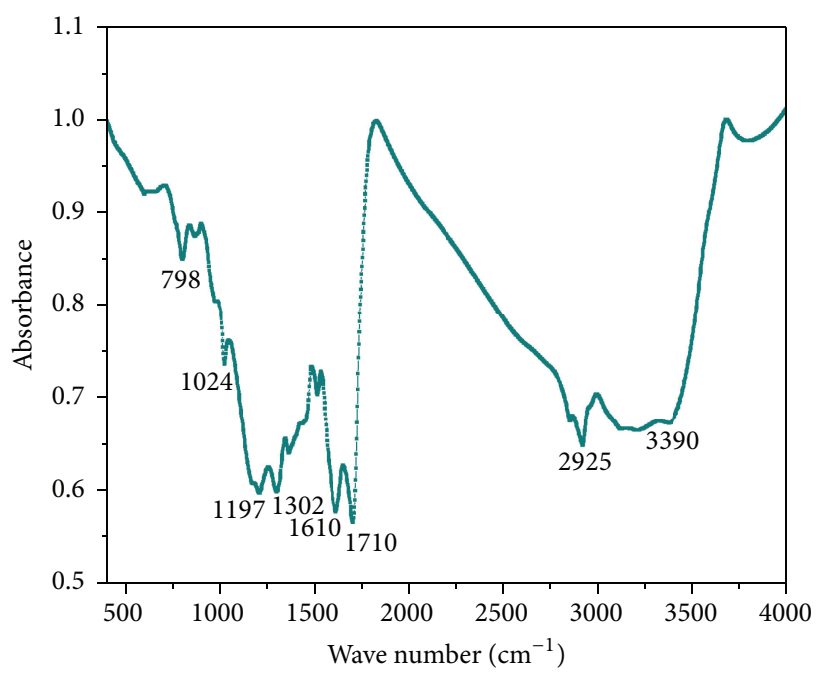

(c)

FIGURE 3: Fourier transform infrared spectroscopy FTIR spectra of carbon spheres. (a) no surfactant; (b) $0.015 \mathrm{~mol}^{2} \mathrm{~L} \mathrm{NH} \cdot \mathrm{H}_{2} \mathrm{O}$; (c) $0.015 \mathrm{~mol} / \mathrm{L}$ CTAB. 


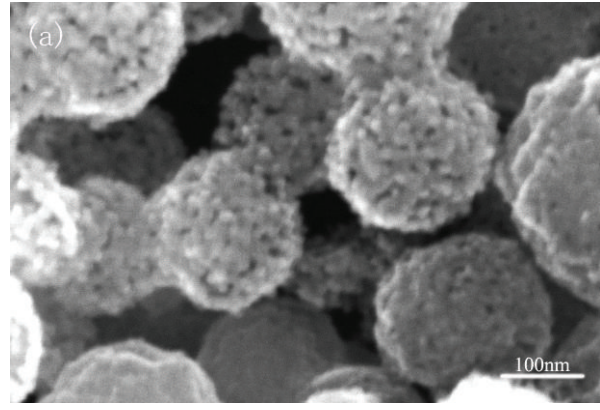

(a)

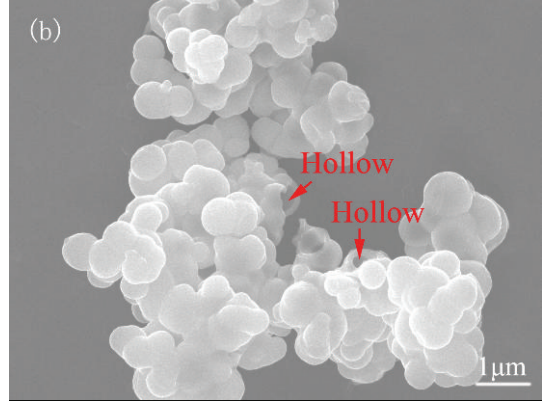

(b)

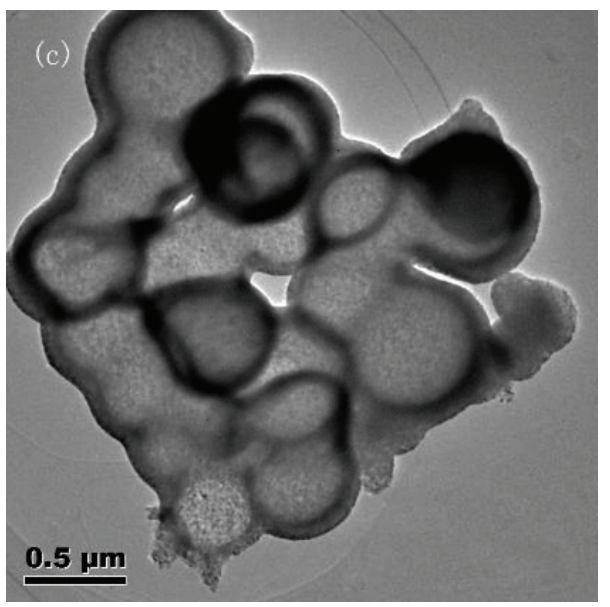

(c)

FIGURE 4: SEM images of (a) as-synthesized carbon-titania composites spheres; (b) titania hollow spheres; (c) TEM image of the titania hollow spheres.

monodispersed carbon spheres with the diameter of $700 \mathrm{~nm}$ can be obtained when adding the $0.015 \mathrm{~mol} / \mathrm{L}$ cetyltrimethylammonium bromide (CTAB) under the hydrothermal conditions of $200^{\circ} \mathrm{C}$ and $10 \mathrm{~h}$ (Table 1 ).

Figure 3 presents the FTIR spectra of the as-synthesized carbon spheres under different conditions. It can be seen clearly that a large number of functional groups exist at the surface of the carbon spheres, including $\mathrm{C}-\mathrm{OH}\left(1710 \mathrm{~cm}^{-1}\right)$, -OH (3300 3500 $\left.\mathrm{cm}^{-1}\right), \mathrm{C}=\mathrm{C}\left(1621 \mathrm{~cm}^{-1}\right), \mathrm{C}=\mathrm{O}\left(1302 \mathrm{~cm}^{-1}\right)$, and $\mathrm{C}-\mathrm{H}\left(2925 \mathrm{~cm}^{-1}\right)$ groups, and, among them, the absorption of the metal ions formed by hydrolysis of inorganic precursors and synergistic reaction with the precursors will be promoted by the presence of the $\mathrm{C}-\mathrm{OH}$ and $-\mathrm{OH}$ groups, while the other groups are harmful to the coating process. Regardless of $\mathrm{NH}_{3} \cdot \mathrm{H}_{2} \mathrm{O}$ and $\mathrm{CTAB}$, the $-\mathrm{OH}$ located at around $3300 \sim 3500 \mathrm{~cm}^{-1}$ decreased when the surfactants were added in the solution, which will affect the subsequent deposition process of metal ions.

3.2. Synthesis of Metal Oxide Hollow Spheres. Figures 4(a) and 4(b) show the SEM images of the carbon-titania composite spheres before and after the thermal treatment at $450^{\circ} \mathrm{C}$ for $4 \mathrm{~h}$, and it can be seen that the coated carbon/ $/ \mathrm{TiO}_{2}$ composite spheres with monodispersed spherical shape were obtained, indicating that the coating layer was uniform. There was a clear contrast between the edge and the center of the assynthesized titania spheres which was observed in the TEM image (Figure 4(c)) indicating that they exhibited a hollow structure. The synthesis mechanism of the titania hollow spheres can be explained as follows. The replacement of the titanate groups and the $-\mathrm{OH}$ of the carbon spheres occurs when the carbon spheres are dispersed in the ethanol, and then the titanium atoms enter the hydrophilic surface of the carbon spheres through a -Ti-O- covalent bond. Once dropped in the mixed solution of water and ethanol, the hydrolysis and condensation reactions of titanate groups in the surface of the carbon spheres will occur, and with the increase of aging time the -Ti-O-Ti- groups are formed on the surface of carbon spheres, which will be trasformed to titania shell after subsequent calcination at certain temperature.

In order to determine the crystal phase of the asprepared hollow $\mathrm{TiO}_{2}$ spheres, XRD measurements were carried out and the results are shown in Figure 5(a). It can be seen that after the calcination of carbon-titania composite spheres at $450^{\circ} \mathrm{C}$ the titania precursor was transformed into anatase $\mathrm{TiO}_{2}$. A distinct large hysteresis loop in the $\mathrm{N}_{2}$ adsorption-desorption isotherms can be observed for all samples (Figure 5(b)), which is a typical IV isotherm with H1-shaped hysteresis loop, demonstrating the presence of 


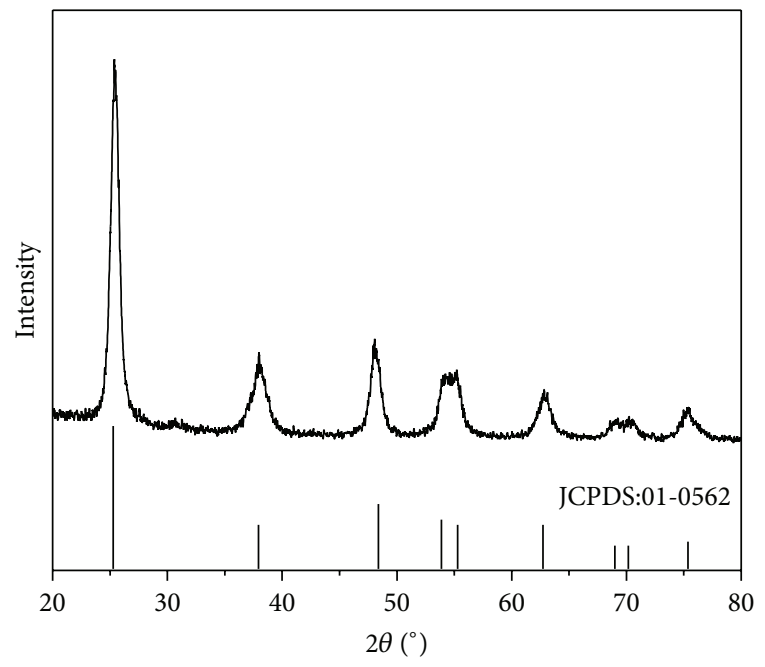

(a)

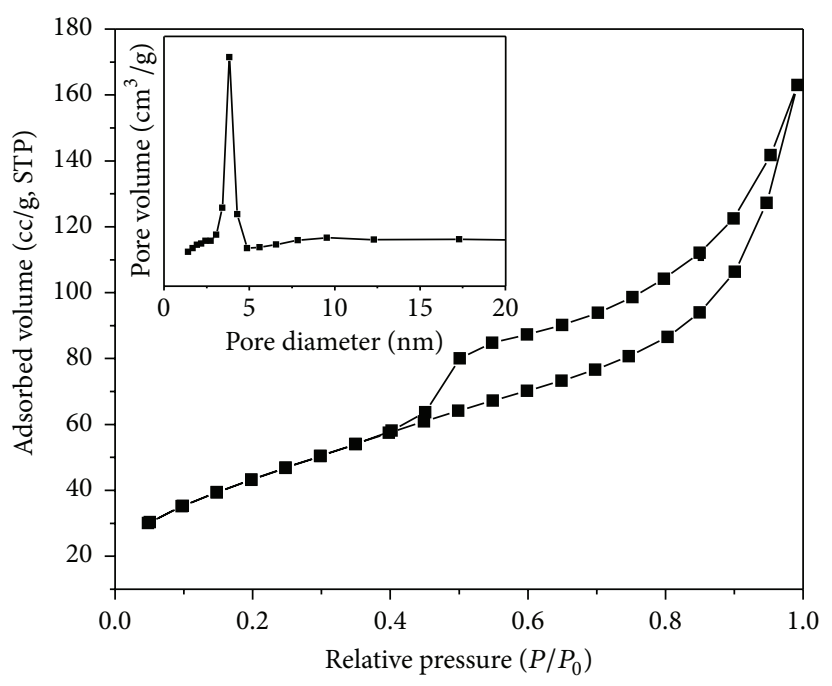

(b)

FIGURE 5: XRD pattern (a) and $\mathrm{N}_{2}$ absorption-desorption isotherms of the titania hollow spheres, and the inset is the pore size distribution curve of the titania hollow spheres (b).

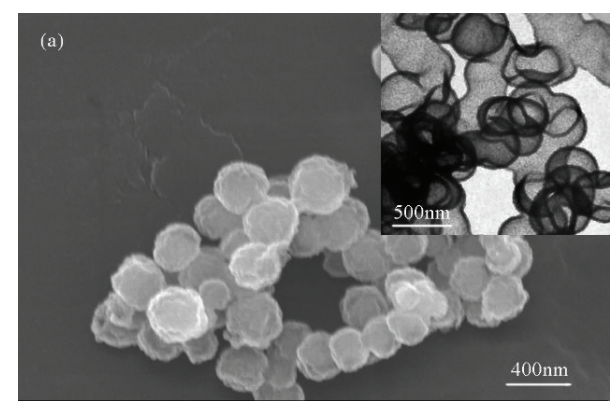

(a)

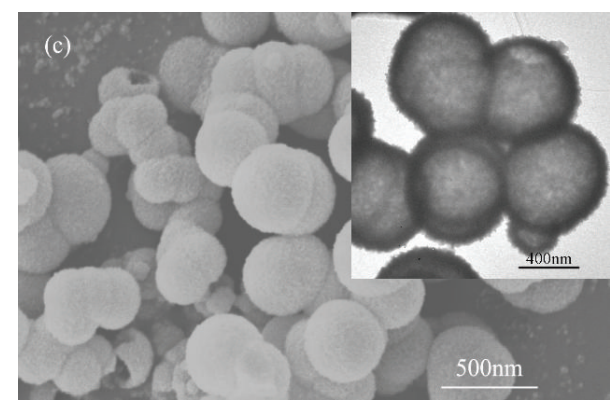

(c)

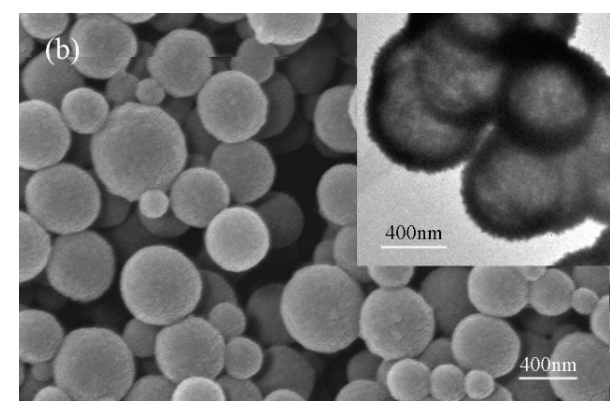

(b)

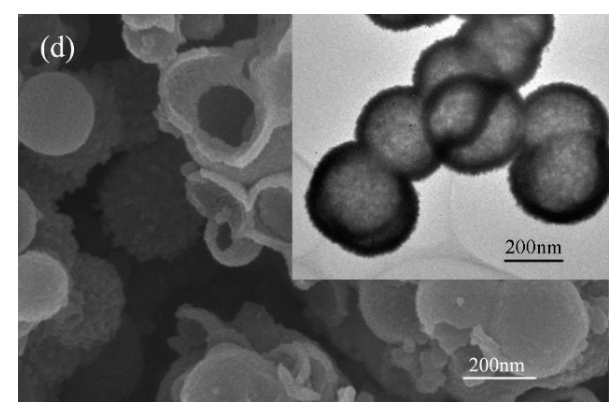

(d)

FIgure 6: SEM images of $\mathrm{SnO}_{2}(\mathrm{a}), \mathrm{Co}_{3} \mathrm{O}_{4}$ (b), YSZ (c), and $\mathrm{CeO}_{2}$ (d) hollow spheres.

mesoporous structure. The titania hollow spheres with the maximum specific surface area of $100.179 \mathrm{~m}^{2} / \mathrm{g}$ and pore volume of $0.110 \mathrm{cc} / \mathrm{g}$ can be obtained when the mass ratio of carbon spheres and tetrabutyl titanate was $1: 30$. The inset in Figure 5(b) shows that the pore size distributions of the hollow spheres exhibits a sharp peak, and the average $\mathrm{BJH}$ mesopore size is $3.76 \mathrm{~nm}$, indicating a uniform mesopore distributed in the shell of the titania hollow spheres.

The size and pore structure of the hollow $\mathrm{TiO}_{2}$ spheres can be easily regulated by adjusting the synthesis parameters.
For example, the diameter of hollow $\mathrm{TiO}_{2}$ spheres can be controlled by using the carbon spheres prepared under different conditions as hard templates, while the wall thickness and specific surface area of the titania hollow spheres can be regulated either by adjusting the concentration of tetrabutyl titanate or by controlling the number of the functional groups located on the surface of the carbon spheres prepared with the presence of surfactants of different types and amount.

The synthesis strategy presented above provides a simple and general approach for the synthesis of hierarchically 
porous metal oxide hollow spheres, which can also be widely applied to other systems. As shown in Figure 6, when other inorganic precursors, such as $\mathrm{SnCl}_{4}, \mathrm{Co}\left(\mathrm{NO}_{3}\right)_{2} \cdot 6 \mathrm{H}_{2} \mathrm{O}$, $\mathrm{Y}\left(\mathrm{NO}_{3}\right)_{3} \cdot 6 \mathrm{H}_{2} \mathrm{O}, \mathrm{ZrOCl}_{2} \cdot 8 \mathrm{H}_{2} \mathrm{O}$, and $\mathrm{Ce}\left(\mathrm{NO}_{3}\right)_{3} \cdot 6 \mathrm{H}_{2} \mathrm{O}$ were employed as templates, the as-prepared $\mathrm{SnO}_{2}, \mathrm{Co}_{3} \mathrm{O}_{4}$, YSZ, and $\mathrm{CeO}_{2}$ hollow spheres with different compositions were successfully prepared by adopting this synthesis strategy. All the prepared hollow spheres with different inorganic salts as precursors possess the well-developed spherical morphology.

\section{Conclusions}

In summary, we have developed a simple and general approach for preparing the metal oxide hollow spheres by using the hydrothermally synthesized colloidal carbon spheres as hard templates. The wall thickness and textural properties of the hollow spheres can be easily tailored by adjusting the concentration of inorganic precursor. The monodispersed hollow spheres with perfect spherical shape and hierarchically pore structures can be used as catalysis, lithium-air battery, fuel cells, gas sensor, and so on.

\section{Conflict of Interests}

The authors declare that there is no conflict of interests regarding the publication of the paper.

\section{Acknowledgments}

The authors would like to thank the financial support from the National Natural Science Foundation of China (NSFC, no. 51202117) and the Fundamental Research Funds for the Central Universities (no. 2014QJ02).

\section{References}

[1] H. C. Zeng, "Synthetic architecture of interior space for inorganic nanostructures," Journal of Materials Chemistry, vol. 16, no. 7, pp. 649-662, 2006.

[2] H. L. Xu and W. Z. Wang, "Template synthesis of multishelled $\mathrm{Cu}_{2} \mathrm{O}$ hollow spheres with a single-crystalline shell wall," Angewandte Chemie-International Edition, vol. 46, no. 9, pp. 1489-1492, 2007.

[3] H. L. Xu, W. Z. Wang, W. Zhu, L. Zhou, and M. L. Ruan, "Nanostructured single-crystalline twin disks of zinc oxide," Crystal Growth \& Design, vol. 7, pp. 541-544, 2007.

[4] D. Zhang, L. Qi, J. Ma, and H. Cheng, "Synthesis of submicrometer-sized hollow silver spheres in mixed polymersurfactant solutions," Advanced Materials, vol. 14, no. 20, pp. 1499-1502, 2002.

[5] Y. Zhao and L. Jiang, "Hollow micro/nanomaterials with multilevel interior structures," Advanced Materials, vol. 21, no. 36, pp. 3621-3638, 2009.

[6] A. D. Dinsmore, M. F. Hsu, M. G. Nikolaides, M. Marquez, A. R. Bausch, and D. A. Weitz, "Colloidosomes: selectively permeable capsules composed of colloidal particles," Science, vol. 298, no. 5595, pp. 1006-1009, 2002.

[7] S. Park, J.-H. Lim, S.-W. Chung, and C. A. Mirkin, "Selfassembly of mesoscopic metal-polymer amphiphiles," Science, vol. 303, no. 5656, pp. 348-351, 2004.
[8] J. V. Ryan, A. D. Berry, M. L. Anderson et al., "Electronic connection to the interior of a mesoporous insulator with nanowires of crystalline $\mathrm{RuO}_{2}$," Nature, vol. 406, no. 6792, pp. 169-172, 2000.

[9] T. K. Maji, R. Matsuda, and S. Kitagawa, "A flexible interpenetrating coordination framework with a bimodal porous functionality," Nature Materials, vol. 6, no. 2, pp. 142-148, 2007.

[10] Y. H. Ao, J. J. Xu, D. G. Fu, and C. W. Yuan, "A simple method for the preparation of titania hollow sphere," Catalysis Communications, vol. 9, no. 15, pp. 2574-2577, 2008.

[11] F. Caruso, "Hollow capsule processing through colloidal templating and self-assembly," Chemistry, vol. 6, no. 3, pp. 413-419, 2000.

[12] J.-J. Zhu, S. Xu, H. Wang, J.-M. Zhu, and H.-Y. Chen, "Sonochemical synthesis of CdSe hollow spherical assemblies via an in-situ template route," Advanced Materials, vol. 15, no. 2, pp. 156-159, 2003.

[13] C. Wang, K. Tang, Q. Yang, J. Hu, and Y. Qian, "Fabrication of BiTeI submicrometer hollow spheres," Journal of Materials Chemistry, vol. 12, no. 8, pp. 2426-2429, 2002.

[14] J.-W. Shi, J.-W. Chen, H.-J. Cui et al., "One template approach to synthesize C-doped titania hollow spheres with high visiblelight photocatalytic activity," Chemical Engineering Journal, vol. 195-196, pp. 226-232, 2012.

[15] C. Wei, G. Zhang, Y. Bai et al., "Al-doped $\mathrm{SnO}_{2}$ hollow sphere as a novel anode material for lithium ion battery," Solid State Ionics, vol. 272, pp. 133-137, 2015.

[16] S. Ding, J. S. Chen, G. Qi et al., "Formation of $\mathrm{SnO}_{2}$ hollow nanospheres inside mesoporous silica nanoreactors," Journal of the American Chemical Society, vol. 133, no. 1, pp. 21-23, 2011.

[17] X. M. Yin, C. C. Li, M. Zhang et al., "One-step synthesis of hierarchical $\mathrm{SnO}_{2}$ hollow nanostructures via self-assembly for high power lithium ion batteries," The Journal of Physical Chemistry C, vol. 114, no. 17, pp. 8084-8088, 2010.

[18] X. Wang, Z. Li, Z. Zhang et al., "Mo-doped $\mathrm{SnO}_{2}$ mesoporous hollow structured spheres as anode materials for highperformance lithium ion batteries," Nanoscale, vol. 7, no. 8, pp. 3604-3613, 2015.

[19] J. G. Yu, W. Liu, and H. G. Yu, "A one-pot approach to hierarchically nanoporous titania hollow microspheres with high photocatalytic activity," Crystal Growth and Design, vol. 8, no. 3, pp. 930-934, 2008.

[20] L. Shen, L. Yu, X.-Y. Yu, X. Zhang, and X. W. D. Lou, "Self-templated formation of uniform $\mathrm{NiCo}_{2} \mathrm{O}_{4}$ hollow spheres with complex interior structures for lithium-Ion batteries and supercapacitors," Angewandte Chemie-International Edition, vol. 54, no. 6, pp. 1868-1872, 2015.

[21] Z. Huang and F. Tang, "Preparation, structure, and magnetic properties of mesoporous magnetite hollow spheres," Journal of Colloid \& Interface Science, vol. 281, no. 2, pp. 432-436, 2005.

[22] X. M. Sun and Y. D. Li, "Colloidal carbon spheres and their core/shell structures with noble-metal nanoparticles," Angewandte Chemie-International Edition, vol. 43, no. 5, pp. 597601, 2004.

[23] M.-M. Titirici, M. Antonietti, and A. Thomas, "A generalized synthesis of metal oxide hollow spheres using a hydrothermal approach," Chemistry of Materials, vol. 18, no. 16, pp. 3808-3812, 2006. 

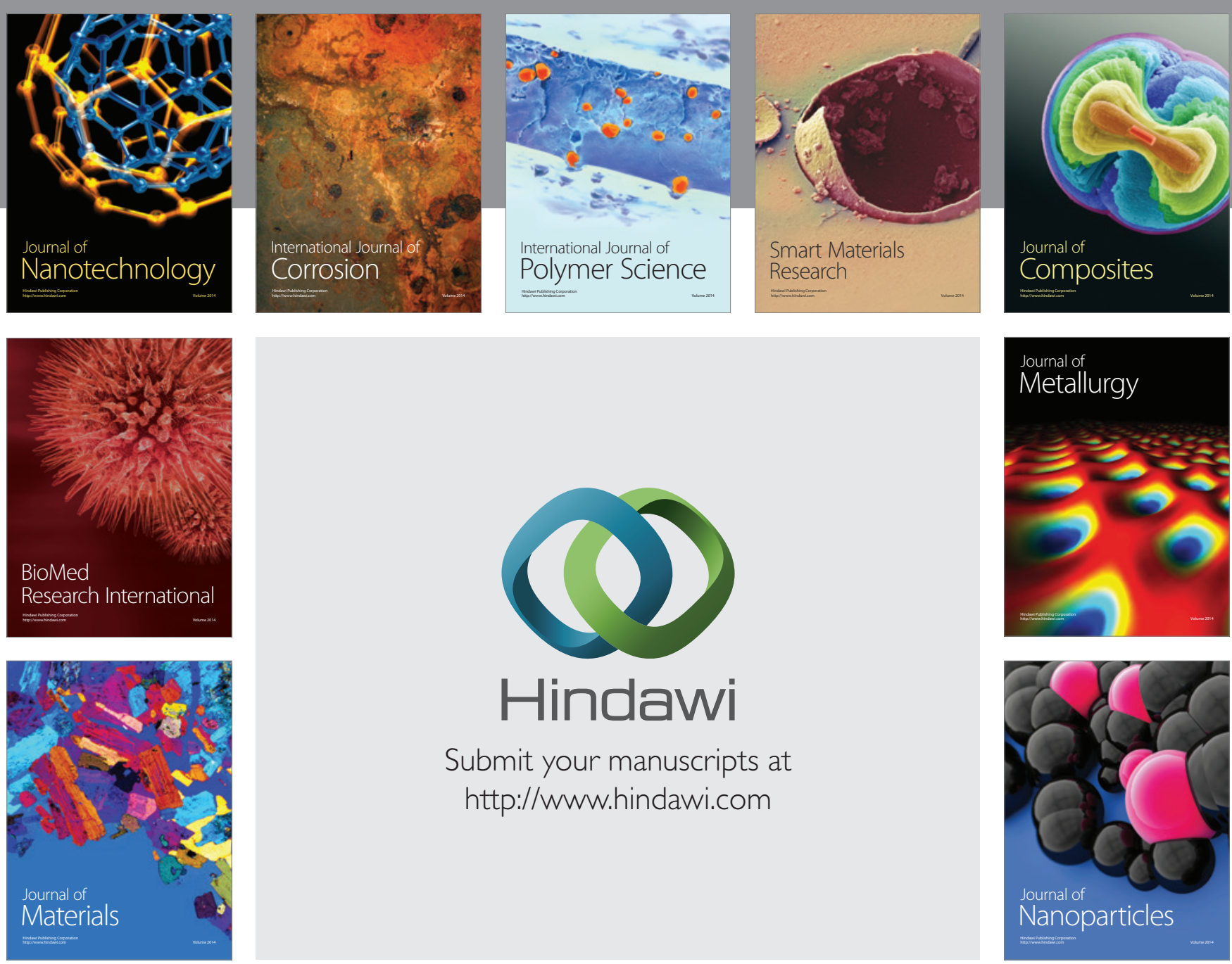

Submit your manuscripts at http://www.hindawi.com
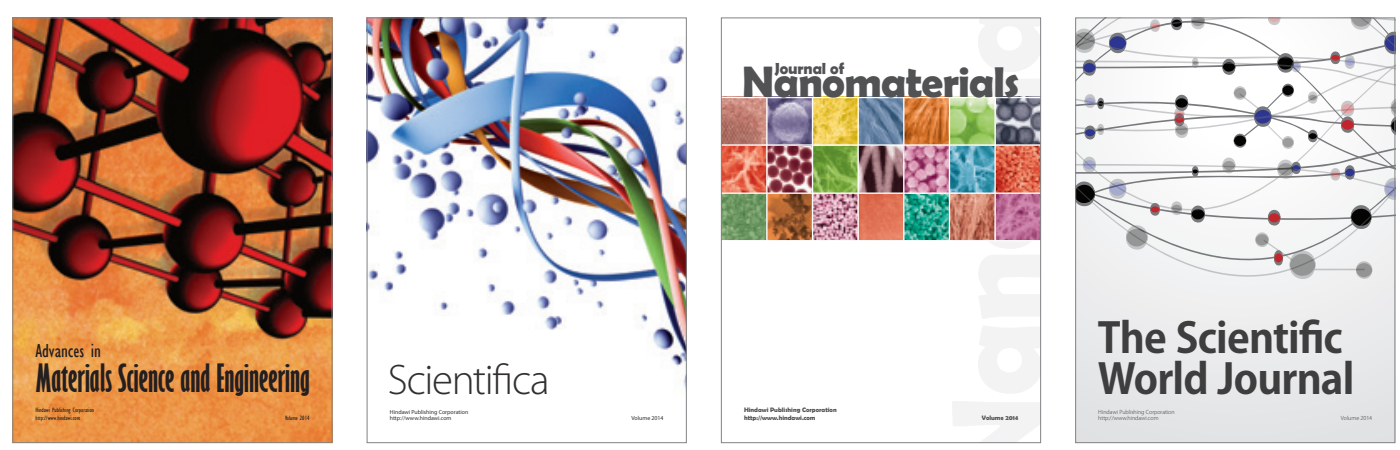

\section{The Scientific World Journal}
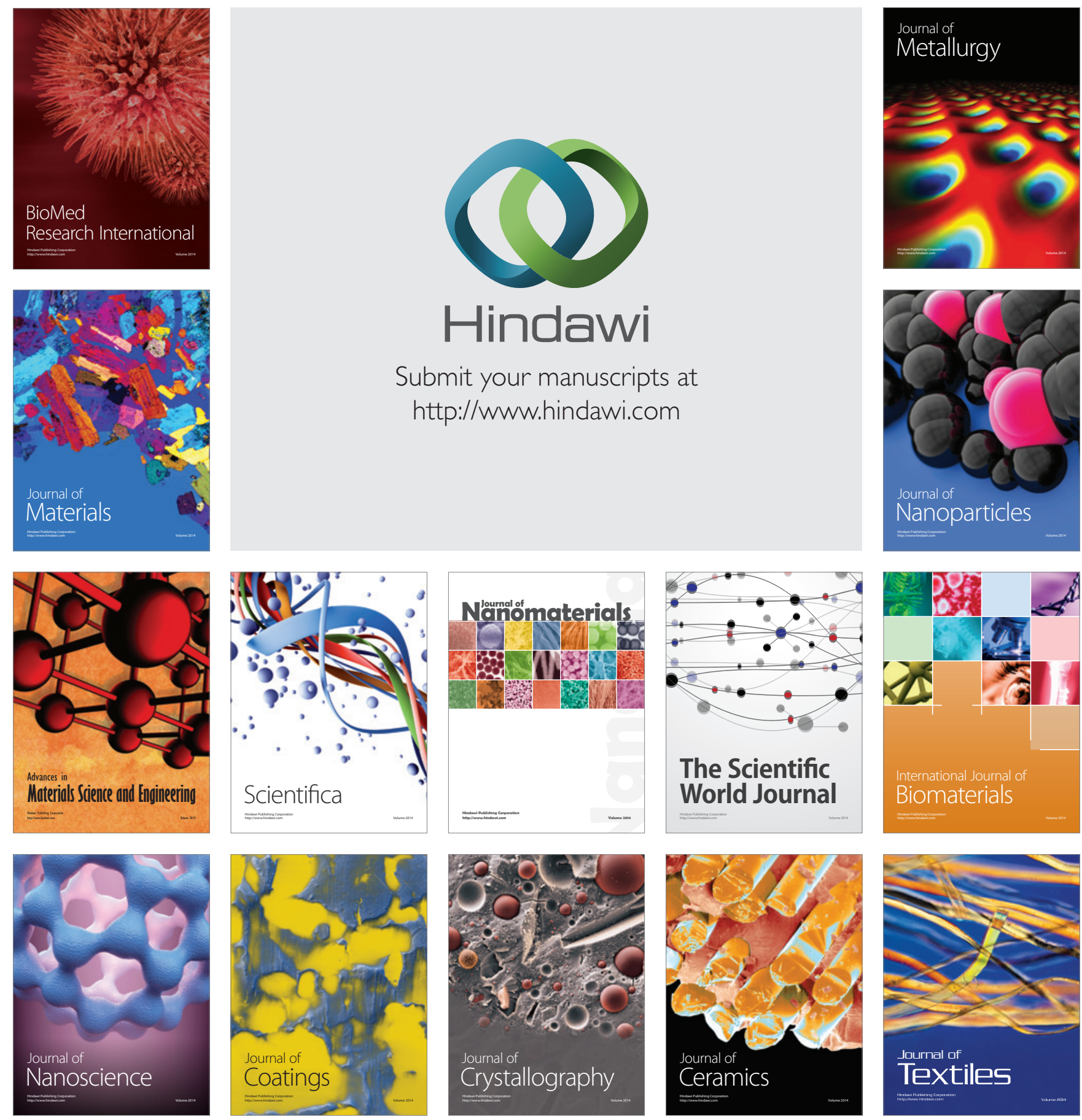